\title{
Research on the Evaluation of University Administration Efficiency
}

\author{
Zhentao Song, Lingling Shi \\ Xi'an Shiyou University, Xi'an, Shaanxi, 710065, China
}

Keywords: Evaluation Method, Administration Status, Efficiency Improvement

\begin{abstract}
With the continuous expansion of the scale of running schools, the continuous improvement of the level of running schools, the continuous improvement of the level of running schools and the continuous deepening of the internal management system, the status and role of administrative management is more prominent, and the tasks are increasingly arduous and complicated. The ever-changing new situation puts higher demands on the administrative work of colleges and universities. Its work efficiency and quality of work directly affect the efficiency and quality of the school's work, and it is also related to the social image and reputation of colleges and universities.
\end{abstract}

\section{Introduction}

Since the reform and opening up, the internal management system of China's colleges and universities has been continuously improved and perfected, and the modern university system has been gradually established. However, we should see the lag in the reform of the internal management system of colleges and universities. Although China's university management system has ushered in a great opportunity for reform since the 1990s, it is an indisputable fact that the development concept of higher education and the reform of internal management system are relatively lagging behind. Because colleges and universities are influenced by the traditional "official standard" thinking, "administrative" institutions of higher learning act in full accordance with the rules of administrative organizations, and managers are always the makers of various policies. Mainly in the position and appointment of various types of personnel in colleges and universities, most colleges have detailed and specific requirements for the setting and appointment conditions of teaching and research posts, while the setting and appointment conditions for other positions such as party and government management are more broad. Rough. Judging from the implementation process, many colleges and universities have adopted a fuzzy approach to party and government management positions when they evaluate the evaluation criteria and assessment requirements of teachers. The manager does not put the personnel with outstanding teaching achievements and scientific research contributions in a prominent position, but instead demonstrates the role of power in the distribution system as much as possible, and formulates some formal indicators according to the subjective will, instead of academic. In the indicator system, such institutional arrangements can not only encourage teaching and research personnel to make more contributions in their own positions, but also force some teaching and research personnel to squat in management positions, thus dissipating limited educational resources, which is not conducive to the healthy development of higher education. .

\section{Characteristics of China's colleges and universities administrative management}

First, university administration and academic management complement each other. The internal affairs of colleges and universities can be divided into academic affairs and administrative affairs. Accordingly, higher education management can be divided into different natures, and two related academic management and administration. University is the hall of knowledge, and academic is the soul of the university. The role of academic management plays a decisive role in management. The main academic management of academic staff and academic organizations in colleges and universities. Academic management includes discipline construction, scientific research, teaching 
activities, teacher training, education and employment, and recruitment. Colleges and universities have academic attributes as well as administrative attributes. "In the process of its development, colleges and universities have formed their own bureaucratic structure, and have their own administrative system, which has administrative attributes." The object of administrative management of colleges and universities is administrative affairs, and the main body is the administrative body of administrative personnel, which mainly includes propaganda and infrastructure. , personnel, organization, logistics and other matters.

Second, the main body of administrative management in colleges and universities presents a trend of specialization. In administrative work, there is often a large amount of professional management, such as teaching, research, and personnel departments. Execution of orders, the organization of these departments on the one hand coordination on the other hand also undertake a certain degree of assessment, identification. Such as quality control, in the process of teaching evaluation, hoof selection, identification of scientific research results, selection of teaching materials and experimental equipment. The work of administrative management requires a certain degree of specialization. Therefore, managers at all levels should have relevant professional knowledge in addition to general management theories and skills in colleges and universities. In other words, managers often have dual office administrative and professional technical positions to ensure the smooth running of administrative work.

Third, the administrative management objects of colleges and universities have diverse characteristics. The university management object involves three groups of students, teachers and employees. The foothold, age characteristics, psychological characteristics of students, and learning needs should be fully considered. The desire for employment is the information needed for administrative management, and it is an important basis for its work. Teachers are the main body of teaching and are also committed to academic and scientific research. Factors such as teaching conditions, academic style construction, academic atmosphere, wages, and opportunities for further study greatly influence their enthusiasm for work. The main responsibility of the university staff is to provide our employees and students with all types of services to solve any problem from the "rear".

\section{Problems in the administration of colleges and universities in China}

The management level refers to the vertical level of management, and the management level refers to the horizontal scope of management. Generally speaking, the less the management level, the higher the efficiency, the smaller the management level, the better the effect, but under certain conditions There are mutually exclusive relationships. If there are few management levels, the management will be large, and the management scope will be small. There is no unified model for the solution of contradictions, but a comprehensive consideration of a series of factors, such as the quality and level of the management team, the nature of the management work, the size of the school, the degree of informationization, the campus setting, the geographical environment, etc. Actual needs, taking into account the management level and management scope.

The establishment and improvement of the market economic system has weakened the planning and unity of higher education, and enhanced market, differentiation and service. Therefore, the original settings of the administrative organization and its functions must be adapted to this and necessary. Change, appropriately adjust institutional settings, withdraw institutions that cannot meet development requirements, add new institutions that are oriented to the market, and strengthen service and personalization. At the same time, it is necessary to extend the administrative management functions and expand the service space. For example, the personnel department strengthens the personnel exchange function and adapts to the change from "unit person" to "social person" management; the graduate distribution department is transformed into the employment guidance and service department. Strengthen service functions such as consultation, counseling, and recommendation; while the financial department conducts daily financial management, it strengthens the functions of capital operation, provides services for the preservation and appreciation of school assets, and enhances the school's strength; the logistics department gradually 
separates from the administrative agencies and establishes a society. Logistics service system. According to the requirements of the socialist market economic system, the functions of the internal administrative organs of the school should be appropriately changed and extended to make it more suitable for the needs of higher education reform.

The two-level management system of the school is a difficult point in the reform of the administrative management system of colleges and universities in recent years. Under the structure of the academic system, how to allocate power and distribute benefits between schools and colleges is a new problem facing Chinese universities. The decentralization of a number of powers originally controlled by the school departments has made the department gradually become an entity with independent school-running ability, which is a development trend. However, the decentralization of such power may also be the decentralization of specific affairs and responsibilities. It is instinctive in the maintenance of vested interests. In practice, the school department may hinder the decentralization of power, which may lead to the unification of the faculty in terms of power and responsibility. At the same time, when the reform environment is still immature, the faculty may also refuse to accept the decentralization power, because if the benefits accompanying these powers are not well reflected, they will become the resistance and shackles of the development of the faculty. Therefore, the reform of the two-level management system of the school (department) must improve some supporting systems and create a benign environment in order to achieve success.

\section{Evaluation method of university administrative management efficiency}

In the 1960s, the US General Accounting Office took the lead in establishing a 3E evaluation method based on economy, efficiency, and effectiveness. This is also the three levels that scholar Fenwick outlined in 1995 to include performance measures. In the late 1960s and early 1970s, the new public administration school raised the social equity values, favored the hard indicators such as economics, and ignored the $3 \mathrm{E}$ evaluation method of fairness and democracy. In the subsequent government performance evaluation system, the Equality indicator was included and gradually developed into the 4E evaluation method summarized by Flynn in 1997. 4E performance metrics build performance indicators by using specific concepts to reflect government performance.

The focus of the $4 \mathrm{E}$ indicator is not the same. As for a certain policy in a certain period of time, the importance and urgency of $4 \mathrm{E}$ are not the same as the intensity. On the contrary, they may often exhibit mutually exclusive and competitive nature (either or the other), which is fundamentally The government's resource allocation, prioritization, and public management and public service concepts for the established target program. The author believes that the "effectiveness" should be used as the criterion for judging the "equity priority, taking into account the efficiency and economy" in order to find out the problems of university administration. Propose a solution.

The selection of performance evaluation indicators for colleges and universities can be selected according to the different classifications of university administration. Some scholars believe that "management is the use of their power and authority by managers in group organizations. It is planned and controlled by most managers and their one-person relationship, person-to-person relationship, and person-to-object relationship. Scheduled goals and activities of the mission". It is also proposed that the content of college management mainly includes eight aspects, namely: goal, task, division of labor, collaboration; planning, organization, control; centralized, unified and hierarchical management; discipline, order; command, obedience; Power, authority; academic democracy, teaching and educating people. These aspects define the key content of university management from multiple perspectives such as basic concepts, starting points, management processes, and checks and balances. Some scholars also pointed out that "the word "governance" means formal or informal arrangements followed by decision-making and action by higher education institutions. It includes external management and internal management. External management deals with higher education institutions. Internal management deals with the distribution of power within institutions of higher learning. The author comprehensively considers the different interpretations of university management by scholars, combined with the actual situation of the author's own colleges and universities, and divides the administrative management 
of colleges and universities into six aspects: (1) fund management; (2) goal management; (3) teaching management; (4) Student management; (5) Personnel management; (6) Public welfare management. The above six management contents are used as indicators for the evaluation of administrative efficiency in colleges and universities. They are divided into four levels: A (excellent), B (good), C (general), and D (bad). Each level is based on four evaluation criteria. To divide: quantity standards, quality standards, effectiveness standards, cost standards. The standard selected the author's college as an empirical study, using the ' $4 \mathrm{E}$ ' evaluation method to examine the administrative performance of SY University.

\section{Conclusion}

This paper uses the literature research method and empirical analysis method to systematically study the administrative efficiency of colleges and universities in China, the evaluation system of university management efficiency, and the improvement measures of university management efficiency. In particular, it starts with the discussion of the attributes of college legal persons, determines the nature of non-profit organizations in colleges and universities, and guides the establishment of the evaluation system of administrative efficiency of universities with the performance management theory of non-profit organizations. It selects fund management, goal management, teaching management, student management, personnel management, Six evaluation indicators, such as public welfare management, combined with the "4E" evaluation method to establish an evaluation model of administrative performance in China's colleges and universities.

\section{References}

[1] Niu Haisheng. Research on University Administration in the View of Knowledge Economy [J]. Heilongjiang Higher Education Research, 2006(6).

[2] Feng Jin. Analysis on how to improve the efficiency of administrative management in colleges and universities [J]. China Management Informationization, 2011 (24).

[3] Li Jin. Strengthening the Management Supervision Mechanism to Promote the Healthy and Orderly Development of Higher Vocational Colleges [J]. Journal of Taiyuan Urban Vocational and Technical College, 2008(12).

[4] Wang Benfeng. Research on the improvement of university management performance [D]. Shandong University of Science and Technology, 2008.

[5] Tian Weimeng. Countermeasures for Improving the Efficiency of Administrative Management in Colleges and Universities [J]. Journal of Xi'an University of Posts and Telecommunications, 2010(4) 